\title{
Compostagem e vermicompostagem de resíduos domiciliares com esterco bovino para a produção de insumo orgânico
}

\author{
Diego Campana Loureiro(1), Adriana Maria de Aquino(2), Everaldo Zonta ${ }^{(1)}$ e Eduardo Lima ${ }^{(1)}$
}

(1)Universidade Federal Rural do Rio de Janeiro. E-mail: diegocalo@gmail.com, ezonta@ufrrj.br, edulima@ufrrj.br (2)Embrapa Agrobiologia, Km 7, Caixa Postal 74.505, CEP 23890-000 Seropédica, RJ. E-mail: adriana@cnpab.embrapa.br

\begin{abstract}
Resumo - O objetivo deste trabalho foi avaliar a produção de adubo orgânico de resíduos domiciliares, por meio da integração de compostagem e vermicompostagem, com e sem esterco bovino nesses processos. Foram realizadas duas etapas experimentais: na primeira, testou-se a termoestabilização dos resíduos e estabeleceram-se condições propícias para a introdução das minhocas; na segunda, aos 27 dias de termoestabilização, os resíduos resultantes da primeira etapa foram colocados em um recipiente de $9 \mathrm{dm}^{3}$, com e sem minhocas, em delineamento inteiramente casualizado, com quatro repetições. Aos 19, 55 e 69 dias, avaliaram-se as taxas de reprodução e sobrevivência das minhocas adultas e os atributos químicos do composto com e sem minhoca. As minhocas sobreviveram e se reproduziram nos substratos, com maior taxa de multiplicação no substrato com esterco. A utilização dos resíduos orgânicos de origem domiciliar, para a produção de insumo, é tecnicamente viável, tanto por meio da compostagem, quanto da vermicompostagem. A adição de esterco não reduziu o tempo de maturação do composto. À exceção do $\mathrm{K}$ e Mg, que tiveram seus teores alterados, a integração dos processos de compostagem e vermicompostagem, com e sem esterco, produziu adubos com características químicas similares.
\end{abstract}

Termos para indexação: minhocas, composto orgânico, reprodução.

\section{Composting and vermicomposting of home residues with bovine manure for organic amendment production}

\begin{abstract}
The objective of this work was to evaluate the production of organic amendment from home residues by integration of composting and vermicomposting processes with and without bovine manure. Two experimental steps were adopted: in the first one, thermal stabilization of the residues and adequate conditions were set up for earthworm introduction; in the second step, at 27 days of thermal stabilization, residues remained from the first step were placed in a $9-\mathrm{dm}^{3}$ container, with and without earthworms, in a completed randomized experimental design of four replicates. Evaluations were made at 19, 55, 69-day period for reproduction and survival rate of adult worms, and chemical attributes of the compost with and without earthworms. Earthworms survived and reproduced in the substrates, and manure gave the highest reproduction rate. The utilization of organic home residues for production of amendment is technically viable by means of composting or vermicomposting. Addition of doses of manure did not decreased the time for compost maturation. Except for the alteration in the levels of $\mathrm{K}$ and $\mathrm{Mg}$, the integration of composting and vermicomposting processes yielded products with similar chemical composition.
\end{abstract}

Index terms: earthworm, organic composting, reproduction.

\section{Introdução}

As áreas urbanas caracterizam-se pela alta produção de resíduos orgânicos, tanto de origem domiciliar quanto de áreas comerciais e industriais como padarias e açougues, entre outras. Esses resíduos geralmente são aterrados, incinerados a temperaturas acima de $900^{\circ} \mathrm{C}$, ou descartados em terrenos baldios, e constituem-se não só em grande preocupação das municipalidades, relacionada ao saneamento ambiental, como também em desperdício de nutrientes.

Os resíduos orgânicos domiciliares são opção para atender aos princípios sanitários e ecológicos. A adequação da reciclagem desses resíduos resolve a questão ambiental e, em contrapartida, promove a geração de insumos orgânicos para a agricultura, o que é um dos aspectos mais importantes envolvidos nesse sistema de produção. 
O aproveitamento dos resíduos orgânicos domiciliares, como adubo para a produção agrícola, requer alguns conhecimentos que possibilitem a adequada forma de prepará-los e que garantam um produto estabilizado e de boa qualidade, que forneça nutrientes e condicione $o$ solo de forma adequada.

A compostagem é um processo de decomposição aeróbica, em que há desprendimento de gás carbônico, água - na forma de vapor - e energia por causa da ação dos microrganismos. Parte da energia é usada pelos microrganismos para crescimento e movimento, e a restante é liberada como calor, que se procura conservar na pilha de compostagem. Como resultado, a pilha atinge uma temperatura elevada, resfria e atinge o estágio de maturação (Kiehl, 1985). O composto, produto da compostagem, é um material homogêneo e relativamente estável (Peixoto et al., 1989). O composto pode, também, passar por um processo de vermicompostagem, que é o resultado da combinação da ação de minhocas e dos microrganismos que habitam seus intestinos, e dar origem ao vermicomposto (Albanel et al., 1988). O esterco pode funcionar como fonte de microrganismos e promover redução do tempo da maturação do composto. De acordo com Singh \& Sharma (2002), a adição de microrganismos favorece a decomposição inicial dos resíduos orgânicos, o que reduz o tempo da vermicompostagem.

Atualmente, o enfoque é na integração dos processos de compostagem e vermicompostagem para otimizar a reciclagem (Ndegwa \& Thompson, 2001; Singh \& Sharma, 2002; Nair \& Sekiozoic, 2006; Tognetti et al., 2005). Ambos os processos compõem um sistema tecnológico de baixo custo, para a transformação de resíduos orgânicos em compostos que podem ter alto valor nutricional para as plantas (Hand et al., 1988) e para a produção de mudas (Alves \& Passoni, 1997).

Estudos têm demonstrado que a vermicompostagem, em comparação ao composto produzido sem as minhocas, acelera a estabilização da matéria orgânica e produz um composto com menor relação $\mathrm{C} / \mathrm{N}$, maior capacidade de troca catiônica e maior quantidade de substâncias húmicas (Albanell et al., 1988) e fitormonais (Tomati et al., 1995). Além disso, a combinação da compostagem com a vermicompostagem reduz o tempo para obtenção do composto (Ndegwa \& Thompson, 2001; Singh \& Sharma, 2002).

O objetivo deste trabalho foi avaliar a viabilidade técnica da produção de adubo orgânico, a partir de resíduos domiciliares, por meio da integração da compostagem e vermicompostagem, com e sem esterco bovino nesses processos.

\section{Material e Métodos}

O experimento foi realizado em duas etapas na Fazendinha Agroecológica, Km 47, em Seropédica, RJ. A primeira, iniciada em abril de 2004, consistiu na compostagem de resíduos, com e sem esterco bovino. Foram utilizados resíduos orgânicos provenientes do restaurante da Universidade Federal Rural do Rio de Janeiro (restos de frutas, casca de cebola, batata, cenoura, guardanapo, arroz, feijão etc.), folhas de mangueira e jambeiro e restos de capina de residência. Os resíduos foram colocados em cilindros de plástico, sustentados por varas de bambu de $1 \mathrm{~m}$ de altura e $0,70 \mathrm{~m}$ de diâmetro, em camadas alternadas e irrigadas. Cada camada de capina e folha ocupou um volume de $60 \mathrm{~L}$, o esterco e restos do restaurante, um volume de $10 \mathrm{~L}$. Cada tratamento recebeu quatro camadas de resíduos, volume total de $560 \mathrm{~L}$ para o tratamento com esterco, e de $520 \mathrm{~L}$ para o tratamento sem esterco. A caracterização química de cada camada está apresentada na Tabela 1 .

A irrigação e o reviramento das pilhas foram realizados depois de 7 e 14 dias do início do experimento, e a temperatura das pilhas foi monitorada.

Foram retiradas amostras aos 7, 14 e 27 dias da compostagem para caracterização química dos substratos, de acordo com o método da Embrapa (1997).

Tabela 1. Caracterização química dos resíduos orgânicos utilizados para a compostagem.

\begin{tabular}{|c|c|c|c|c|c|c|c|c|c|}
\hline Resíduos orgânicos & C & $\mathrm{N}$ & $\mathrm{Ca}$ & $\mathrm{Mg}$ & $\mathrm{P}$ & $\mathrm{K}$ & Matéria orgânica & $\begin{array}{l}\text { Umidade } \\
\qquad(\%)\end{array}$ & $\begin{array}{c}\text { Relação } \\
\text { C/N }\end{array}$ \\
\hline Restos de capina & 488,4 & 22,9 & 6,4 & 3,6 & 2,1 & 11,0 & 842,1 & 18,4 & 21 \\
\hline Folhas de jambeiro & 502,6 & 8,8 & 34,4 & 3,9 & 0,3 & 1,2 & 866,5 & 14,1 & 57 \\
\hline Folhas de mangueira & 467,8 & 8,2 & 15,4 & 2,2 & 0,3 & 1,4 & 806,6 & 15,0 & 56 \\
\hline Restaurante universitário & 453,7 & 29,7 & 4,8 & 1,4 & 2,2 & 8,5 & 782,3 & 80,4 & 15 \\
\hline Esterco bovino & 444,4 & 20,4 & 14,1 & 8,0 & 5,0 & 23,0 & 766,2 & 65,5 & 22 \\
\hline
\end{tabular}


Na temperatura de $22^{\circ} \mathrm{C}$, que ocorreu após 27 dias da compostagem, em maio de 2004, iniciou-se a segunda etapa do experimento com os resíduos provenientes da etapa anterior.

Foram testados os tratamentos: resíduos orgânicos com esterco e com minhoca; e resíduos orgânicos sem esterco, com e sem minhoca. O delineamento experimental adotado foi o inteiramente casualizado, com quatro repetições, no esquema de parcelas subdivididas no tempo. Os resíduos foram colocados em caixas de $9 \mathrm{dm}^{3}$, cobertas com restos de capina para manutenção da umidade. Nos tratamentos de vermicompostagem, foram adicionadas 20 minhocas adultas da espécie Eisenia andrei (Bouche), com peso médio de 0,36 e 0,50 g. Essa espécie de minhoca é muito semelhante, morfologicamente, à conhecida como vermelha-da-califórnia, que pertence à espécie Eisenia foetida (Dominguéz et al., 2005).

Aos 69 dias após o processo de vermicompostagem, foram retiradas amostras dos substratos para sua caracterização química (Embrapa, 1997).

Os substratos de cada tratamento foram secados à temperatura ambiente, passados em peneiras (tamis) de malha de 8 e $2 \mathrm{~mm}$, e foi quantificado o volume que passou no tamis de malha de $2 \mathrm{~mm}$, o retido pelo tamis de $8 \mathrm{~mm}$ e o total de substrato com e sem esterco, e com e sem minhocas.

A adaptação das minhocas e sua capacidade reprodutiva foi avaliada aos 19, 55 e 69 dias da vermicompostagem, por meio da contagem do número das minhocas adultas, das juvenis e dos casulos.

Foi realizada a análise de variância para as seguintes variáveis: carbono total, nitrogênio total, relação $\mathrm{C} / \mathrm{N}$, cálcio, magnésio, fósforo, potássio, número de minhocas juvenis e número de casulos. Os dados referentes ao nitrogênio foram transformados por log $(\mathrm{x})$, para atender aos pressupostos da análise de variância. Para análise de variância, utilizou-se o Sisvar (Ferreira, 2000). Para o fator presença de esterco, foi utilizado o teste de comparação de médias (Scott-Knott); para o fator época, foi utilizada a regressão linear.

\section{Resultados e Discussão}

$\mathrm{Na}$ primeira etapa do processo, que consistiu na termoestabilização dos resíduos domésticos com e sem esterco, a temperatura atingiu $40-50^{\circ} \mathrm{C}$, entre 7 e 15 dias após o início do processo (Figura 1), o que indica atividade de bactérias e fungos termofílicos na degradação dos resíduos. Entre 20 e 27 dias, a temperatura variou de 22 a $30^{\circ} \mathrm{C}$. Essa temperatura indica a colonização de fungos e actinomicetos no composto (Madaleno, 2002).

Aos 27 dias da compostagem, a relação $\mathrm{C} / \mathrm{N}$ do resíduo doméstico com esterco foi maior do que a do resíduo sem esterco (Tabela 2). A mineralização dos resíduos orgânicos com esterco foi mais intensa do que no tratamento sem esterco, o que provocou maior lixiviação de formas iônicas de nitrogênio, após o período chuvoso que ocorreu antes da amostragem. No entanto, no tratamento sem esterco, em que a mineralização estava menos intensa, o nitrogênio encontrava-se ainda em formas orgânicas não lixiviáveis. O processo de compostagem origina-se da atividade de microrganismos que convertem o nitrogênio em $\mathrm{NH}_{3}$, durante a decomposição do material orgânico, o que diminui o teor de nitrogênio do composto, pois o esterco fornece os microrganismos que aceleram a decomposição da matéria orgânica, libera nutrientes e, conseqüentemente, formas iônicas de nitrogênio sujeitas à lixiviação, à

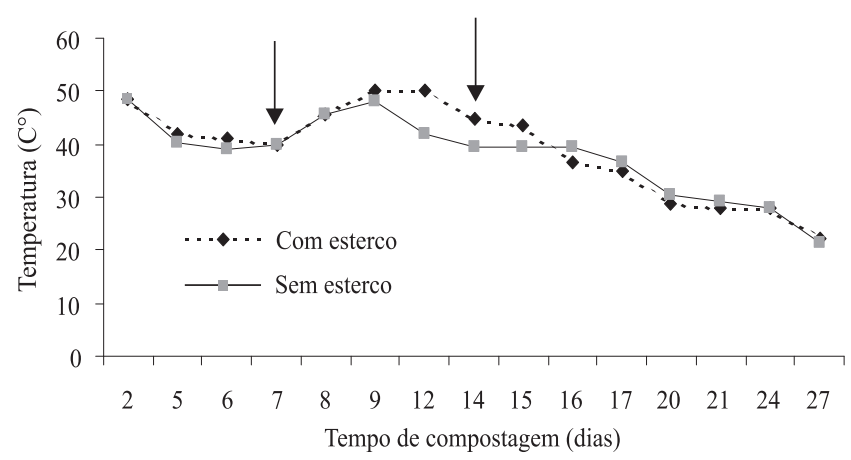

Figura 1. Evolução da temperatura durante a compostagem. As setas indicam as épocas em que as pilhas foram reviradas.

Tabela 2. Caracterização química dos resíduos orgânicos domiciliares, com e sem esterco, aos 7, 14 e 27 dias de compostagem $^{(1)}$.

\begin{tabular}{|c|c|c|c|c|c|c|}
\hline \multirow[t]{3}{*}{ Caracterização } & \multicolumn{6}{|c|}{ Dias } \\
\hline & \multicolumn{2}{|c|}{7} & \multicolumn{2}{|c|}{14} & \multicolumn{2}{|c|}{27} \\
\hline & Com & Sem & Com & Sem & Com & Sem \\
\hline $\mathrm{C}\left(\mathrm{g} \mathrm{kg}^{-1}\right)$ & $306 \mathrm{~A}$ & $285 \mathrm{~A}$ & $265 \mathrm{~A}$ & $275 \mathrm{~A}$ & $194 \mathrm{~A}$ & $154 \mathrm{~A}$ \\
\hline $\mathrm{N}\left(\mathrm{g} \mathrm{kg}^{-1}\right)$ & $18 \mathrm{~A}$ & $19 \mathrm{~A}$ & $16 \mathrm{~A}$ & $18 \mathrm{~A}$ & $9 \mathrm{~A}$ & $11 \mathrm{~A}$ \\
\hline $\mathrm{C} / \mathrm{N}$ & $17 \mathrm{~A}$ & $16 \mathrm{~A}$ & $18 \mathrm{~A}$ & $16 \mathrm{~A}$ & $22 \mathrm{~A}$ & $14 \mathrm{~B}$ \\
\hline $\mathrm{Ca}\left(\mathrm{g} \mathrm{kg}^{-1}\right)$ & $17 \mathrm{~A}$ & $11 \mathrm{~B}$ & $14 \mathrm{~A}$ & $15 \mathrm{~A}$ & $10 \mathrm{~A}$ & 9 \\
\hline $\operatorname{Mg}\left(\mathrm{g} \mathrm{kg}^{-1}\right)$ & $3,6 \mathrm{~A}$ & $2,2 \mathrm{~B}$ & $2,7 \mathrm{~A}$ & $2,8 \mathrm{~A}$ & $2,0 \mathrm{~A}$ & $1,8 \mathrm{~A}$ \\
\hline $\mathrm{P}\left(\mathrm{g} \mathrm{kg}^{-1}\right)$ & $2,1 \mathrm{~A}$ & $1,9 \mathrm{~A}$ & $1,9 \mathrm{~A}$ & $1,8 \mathrm{~A}$ & $1,8 \mathrm{~A}$ & $1,3 \mathrm{~A}$ \\
\hline $\mathrm{K}\left(\mathrm{g} \mathrm{kg}^{-1}\right)$ & $7,7 \mathrm{~A}$ & $6,3 \mathrm{~B}$ & $4,7 \mathrm{~A}$ & $4,7 \mathrm{~A}$ & $3,2 \mathrm{~A}$ & $3,2 \mathrm{~A}$ \\
\hline
\end{tabular}

${ }^{(1)}$ Médias seguidas por letras iguais na linha, dentro da mesma época, não diferem entre si, a 5\% de probabilidade, pelo teste de Scott-Knott. 
volatilização e à utilização pelos microrganismos (Galbally \& Roy, 1983; Moller \& Schieferdecker, 1985).

A adição de esterco não alterou o conteúdo de $\mathrm{N}$ ou $\mathrm{C}$ orgânico, o que indica que o produto da compostagem estava praticamente estável. Isso pôde ser observado após a segunda etapa do processo, em que os tratamentos com e sem esterco apresentaram a mesma relação $\mathrm{C} / \mathrm{N}$ (Tabela 3). Observou-se que o esterco influenciou positivamente apenas o teor de $\mathrm{Mg}$, e negativamente o teor de $\mathrm{K}$ após a vermicompostagem, contudo, não promoveu alteração dos demais nutrientes avaliados (Tabela 3).

A qualidade do vermicomposto, em termos de concentração de nutrientes e efeito na produtividade das plantas, não pode ser generalizada porque depende dos resíduos usados e da tecnologia empregada (Tognetti et al., 2005).

A relação $\mathrm{C} / \mathrm{N}$ é o parâmetro tradicionalmente considerado para se determinar o grau de maturidade do composto e definir sua qualidade agronômica.

Tabela 3. Caracterização química de resíduos orgânicos domiciliares, com esterco e com minhoca, e sem esterco com e sem minhocas ${ }^{(1)}$.

\begin{tabular}{lccccccc}
\hline $\begin{array}{l}\text { Esterco/ } \\
\text { minhoca }\end{array}$ & $\mathrm{C} / \mathrm{N}$ & $\mathrm{C}$ & $\mathrm{N}$ & $\begin{array}{c}\mathrm{Ca} \\
\mathrm{Ca}\end{array}$ & $\mathrm{P}$ & $\mathrm{K}$ \\
\hline $\mathrm{Com} / \mathrm{com}$ & $13 \mathrm{a}$ & $130,0 \mathrm{a}$ & $10,0 \mathrm{a}$ & $9,9 \mathrm{a}$ & $2,2 \mathrm{~b}$ & $1,2 \mathrm{a}$ & $2,1 \mathrm{a}$ \\
$\mathrm{Sem} / \mathrm{com}$ & $12 \mathrm{a}$ & $135,0 \mathrm{a}$ & $11,0 \mathrm{a}$ & $9,7 \mathrm{a}$ & $1,7 \mathrm{a}$ & $0,9 \mathrm{a}$ & $1,9 \mathrm{a}$ \\
$\mathrm{Sem} / \mathrm{sem}$ & $13 \mathrm{a}$ & $141,0 \mathrm{a}$ & $11,0 \mathrm{a}$ & $11,9 \mathrm{a}$ & $1,8 \mathrm{a}$ & $1,0 \mathrm{a}$ & $2,8 \mathrm{~b}$
\end{tabular}

${ }^{(1)}$ Médias seguidas por letras iguais na coluna, não diferem entre si a $5 \%$ de probabilidade, pelo teste de Scott-Knott.
O processo de decomposição e transformação dos resíduos, com e sem minhocas, resultou numa relação $\mathrm{C} / \mathrm{N}$ em torno de 12 (Tabela 3), o que indica a maturidade do composto (Kiehl, 1985) e as condições ideais para adubação.

Em conseqüência da atividade dos microrganismos presentes no esterco e das minhocas, o vermicomposto com esterco ficou com aparência diferente do tratamento sem esterco e sem minhocas, e apresentou maior volume de material mais decomposto (Figuras 2 e 3), o que favorece sua comercialização e manejo.

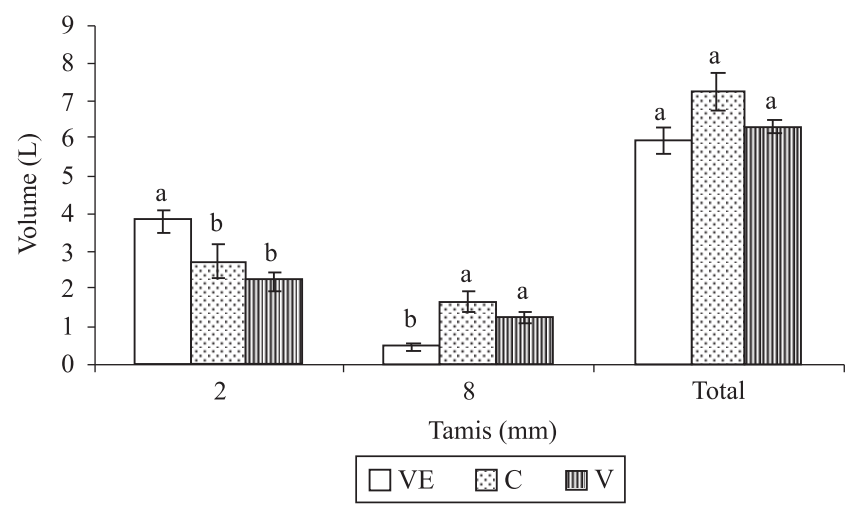

Figura 2. Volume passado no tamis de $2 \mathrm{~mm}$, retido pelo tamis de $8 \mathrm{~mm}$ e o total de substrato com e sem esterco, e com e sem minhocas, após 69 dias da segunda fase do experimento (volume inicial de $9 \mathrm{~L}$ ). Médias com letras iguais não diferem entre si a 5\% de probabilidade, pelo teste de Scott-Knott. VE: vermicomposto com esterco; C: composto sem esterco; $\mathrm{V}$ : vermicomposto sem esterco.

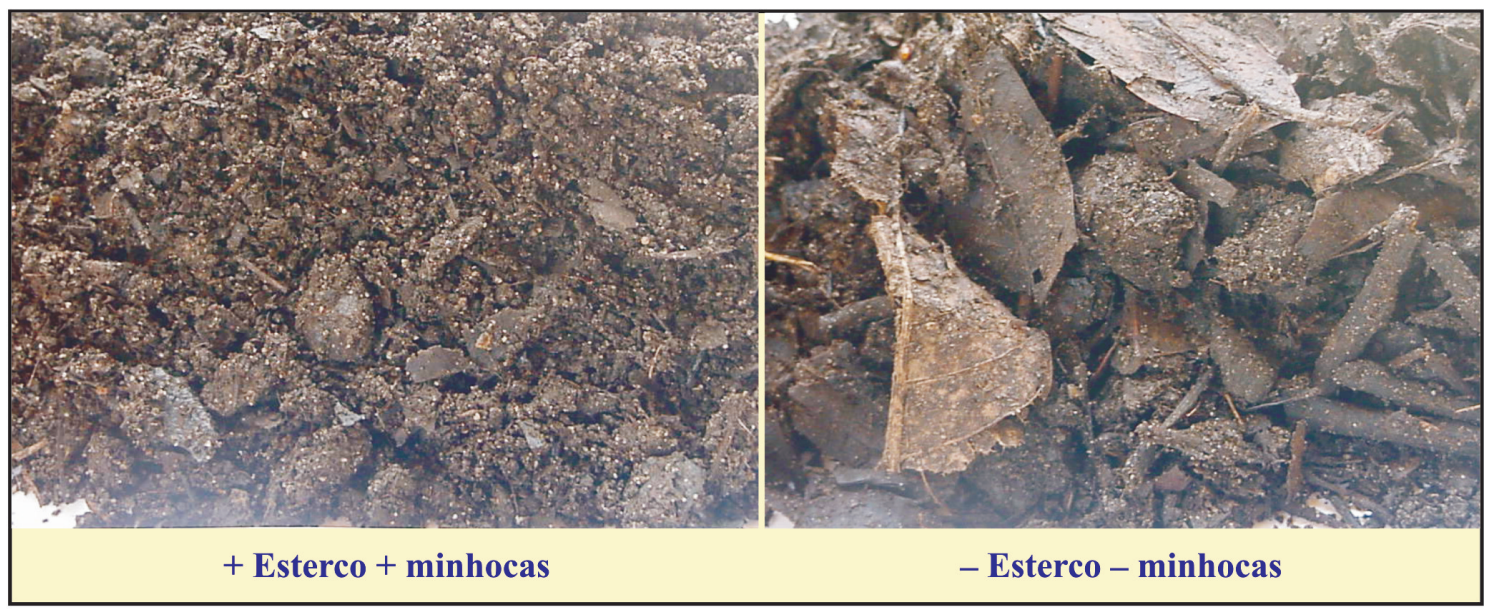

Figura 3. Aparência dos substratos com esterco e com minhocas e sem esterco e sem minhocas, após 69 dias da segunda fase do experimento. 
O processo de vermicompostagem leva à mortalidade das minhocas adultas, como resultado da falta de alimento decorrente da produção do húmus. Em razão disso, a redução da densidade das minhocas adultas é esperada, como observada por Aquino et al. (1994). Entretanto, neste trabalho, a mistura de resíduos orgânicos, com e sem esterco, manteve a população inicial das minhocas adultas, mesmo após 69 dias do início da vermicompostagem.

Uma das grandes vantagens obtidas com a integração dos processos foi que as minhocas além de sobreviverem nos resíduos domiciliares orgânicos, após a estabilização da temperatura, produziram os seus casulos mesmo no substrato sem esterco (Figura 4). Apesar de a produção
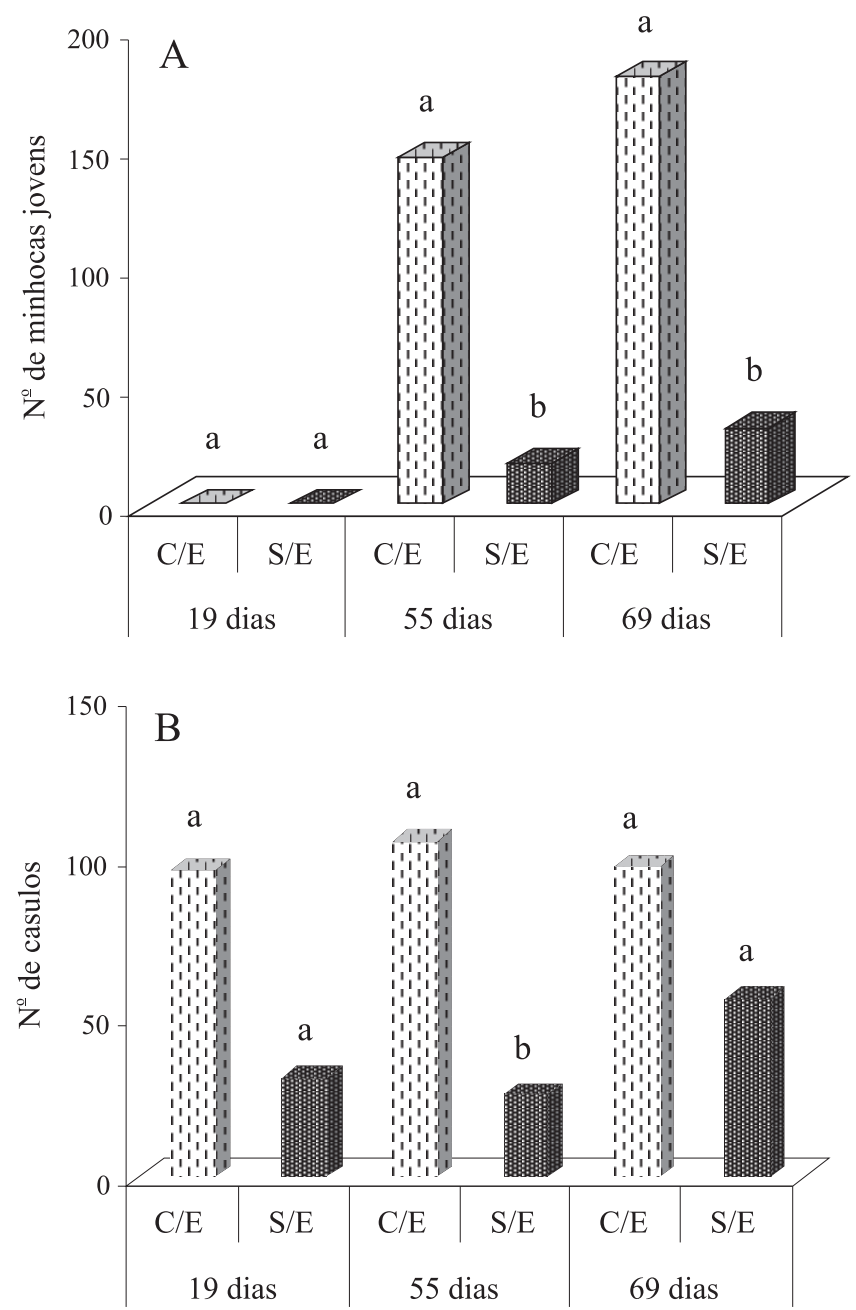

Figura 4. Número de minhocas juvenis (A) e de casulos (B) produzidos durante a vermicompostagem de resíduos orgânicos domésticos, com e sem esterco. Médias seguidas por letras iguais, dentro da mesma época, não diferem entre si a 5\% de probabilidade, pelo teste de Scott-Knott. C/E e S/C referem-se a com esterco e sem esterco, respectivamente. de juvenis ter sido maior no tratamento com esterco, a ausência dele não inviabilizou a reprodução e não limitou a sobrevivência das minhocas.

Após a vermicompostagem, foram observadas 376 minhocas juvenis e 410 casulos, dos quais 86 e $72 \%$, respectivamente, foram produzidos nos tratamentos com esterco. O número de minhocas juvenis, encontrado no tratamento com esterco, diferiu significativamente daquele sem esterco, mas não diferiu significativamente quanto ao número de casulos (Tabela 4). Tripathi \& Bhardwaj (2004) postulam que Eisenia foetida é adaptada para a decomposição de resíduos orgânicos domésticos com esterco. O mesmo foi observado para a espécie E. andrei, utilizada neste trabalho (Figura 5).

A qualidade dos estercos varia com o regime alimentar do bovino e do manejo do rebanho, o que dificulta, algumas vezes, comparações com outros resultados. Mas, de maneira geral, tem-se observado que as minhocas

Tabela 4. Análise de variância da compostagem dos resíduos orgânicos com e sem esterco, em três épocas.

\begin{tabular}{lccc}
\hline \multirow{2}{*}{ Variável analisada } & \multicolumn{3}{c}{ Fontes de variação } \\
\cline { 2 - 4 } & Esterco & Época & Esterco x Época \\
\hline Carbono & $0,3940^{\mathrm{ns}}$ & $0,0050^{*}$ & $0,6648^{\mathrm{ns}}$ \\
Nitrogênio & $0,0268^{*}$ & $0,0025^{*}$ & $0,7932^{\mathrm{ns}}$ \\
C/N & $0,0657^{\mathrm{ns}}$ & $0,5854^{\mathrm{ns}}$ & $0,1982^{\mathrm{ns}}$ \\
Cálcio & $0,2339^{\mathrm{ns}}$ & $0,0725^{\mathrm{ns}}$ & $0,2317^{\mathrm{ns}}$ \\
Magnésio & $0,0729^{\mathrm{ns}}$ & $0,0039^{*}$ & $0,0122^{*}$ \\
Fósforo & $0,0665^{\mathrm{ns}}$ & $0,0993^{\mathrm{ns}}$ & $0,4720^{\mathrm{ns}}$ \\
Potássio & $0,2051^{\mathrm{ns}}$ & $0,0000^{*}$ & $0,0745^{\mathrm{ns}}$ \\
№ de minhocas juvenis & & & \\
na vermicompostagem & $0,0024^{*}$ & $0,0000^{*}$ & $0,0020^{*}$ \\
№ de casulos na & & & \\
vermicompostagem & $0,0963^{\mathrm{ns}}$ & $0,5557^{\mathrm{ns}}$ & $0,3568^{\mathrm{ns}}$ \\
\hline
\end{tabular}

${ }^{n s}$ Não-significativo. Significativo a $5 \%$ de probabilidade.

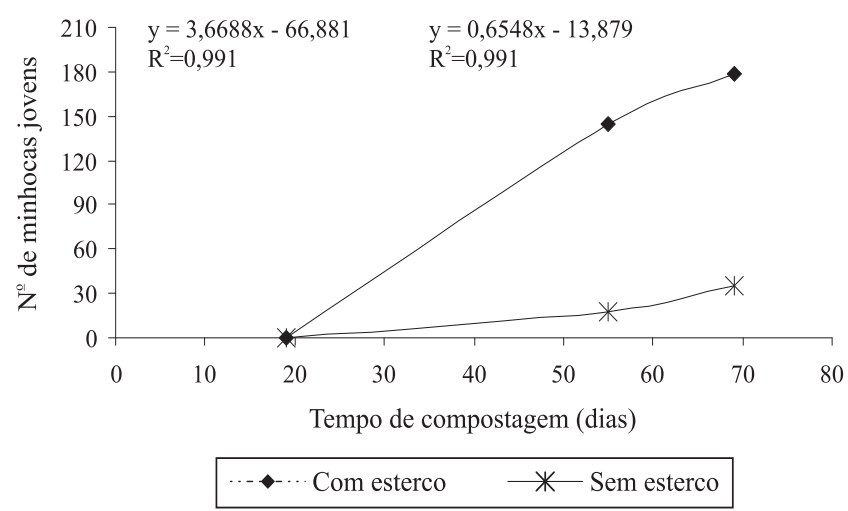

Figura 5. Análise de regressão do número de minhocas jovens, em conseqüência da presença de esterco. 
adaptam-se muito bem ao esterco bovino e a outros substratos misturados ao esterco (Aquino et al., 1994; Kaushik \& Garg, 2004; Pereira \& Azevedo, 2005). Porém, os estercos podem ser escassos nas áreas urbanas; nesse caso, a reciclagem dos resíduos domiciliares, por meio da vermicompostagem, pode limitar a proliferação das minhocas, mas atende à produção de adubo.

\section{Conclusões}

1. A termoestabilização dos resíduos orgânicos domiciliares garante condições para a vermicompostagem.

2. A utilização dos resíduos orgânicos de origem domiciliar para a produção de insumo é tecnicamente viável, tanto por meio da compostagem quanto da vermicompostagem.

3. As minhocas sobrevivem e se reproduzem nos substratos, e o esterco é o que possibilita a maior taxa de multiplicação.

4. A adição de esterco, na dosagem utilizada neste trabalho, não reduz o tempo de maturação do composto.

5. A integração dos processos de compostagem e vermicompostagem com e sem esterco produz adubos com características químicas similares.

\section{Agradecimentos}

Ao CNPq, por bolsa concedida; à Embrapa, pelo financiamento do Projeto.

\section{Referências}

ALBANELL, E.; PLAIXATS, J.; CABRERO, T. Chemical changes during vermicomposting (Eisenia fetida) of sheep manure mixed with cotton industrial wastes. Biology and Fertility of Soils, v.6, p.266269,1988

ALVES, W.L.; PASSONI, A.A. Composto e vermicomposto de lixo urbano na produção de mudas de oiti (Licania tomentosa Benth.) para arborização. Pesquisa Agropecuária Brasileira, v.32, p.58-62, 1997.

AQUINO, A.M. de; ALMEIDA, D.L. de; FREIRE, L.R.; DE-POLLI, H. Reprodução de minhocas (Oligochaeta) em esterco bovino e bagaço de cana-de-açúcar. Pesquisa Agropecuária Brasileira, v.29, p.161168, 1994.

DOMÍNGUEZ, J.; VELANDO, A.; FERREIRO, A. Are Eisenia fetida (Savigny, 1826) and Eisenia andrei Bouché (1972) (Oligochaeta, Lumbricidae) different biological species? Pedobiologia, v.49, p.81-87, 2005.
EMBRAPA. Centro Nacional de Pesquisa de Solos. Manual de métodos de análises de solos. 2.ed. Rio de Janeiro: Embrapa-CNPS, 1997. 212p.

FERREIRA, D.F. Manual do sistema Sisvar para análises estatísticas. Lavras: Universidade Federal de Lavras, 2000. 66p.

GALBALLY, I.E.; ROY, C.R. The fate of nitrogen compounds in the atmosphere. In: FRENEY, J.R.; SIMPSON, J.R. (Ed.). Gaseous loss of nitrogen from plant-soil systems. Hague: Martinus Nijhoff, 1983. p.265-284.

HAND, P.; HAYES, W.A.; FRANKLAND, J.C.; SATCHELL, J.E. Vermicomposting of cow slurry. Pedobiologia, v.31, p.199-209, 1988.

KAUSHIK, P.; GARG, V.K. Dynamics of biological and chemical parameters during vermicomposting of solid textile mill sludge mixed with cow dung and agricultural residues. Bioresource Technology, v.94, p.203-209, 2004.

KIEHL, E.J. Fertilizantes orgânicos. Piracicaba: Agronômica Ceres, 1985. 492p.

MADALENO, I.M. A cidade das mangueiras: agricultura urbana em Belém do Pará. Lisboa: Fundação Calouste Gulbekian, Fundação para a Ciência e a Tecnologia, 2002. 193p.

MOLLER, D.; SHIEFERDECKER, H. A relationship between agricultural $\mathrm{NH}_{3}$ emissions and the atmospheric $\mathrm{SO}_{2}$ content over industrial areas. Atmospheric Environment, v.19, p.695-700, 1985.

NAIR, J.; SEKIOZOIC, M. Effect of pre-composting on vermicomposting of kitche waste. Bioresources Technology, v.16, p.2091-2095, 2006.

NDEGWA, P.M.; THOMPSON, S.A. Integrating composting and vermicomposting in the treatment and bioconversion of biosolids. Bioresource Technology, v.76, p.107-112, 2001.

PEIXOTO, R.T. dos G.; ALMEIDA, D.L. de; FRANCO, A.A. Compostagem de lixo urbano enriquecido com fontes de fósforo. Pesquisa Agropecuária Brasileira, Brasília, v.24, p.599-606, 1989.

PEREIRA, E.W.; AZEVEDO, C.M.S.B. Produção de vermicomposto em diferentes proporções de esterco bovino e palha de carnaúba. Caatinga, v.18, p.112-116, 2005.

SINGH, A.; SHARMA, S. Composting of a crop residue through treatment with microorganisms and subsequent vermicomposting. Bioresource Technology, v.85, p.107-115, 2002.

TOGNETTI, C.; LAOS, F.; MAZZARINO, M.J.; HERNANDES, M.T. Composting vs. vermicomposting: a comparison of end product quality. Compost Science \& Utilization, v.13, p.6-13, 2005.

TOMATI, U.; GALLI, E.; PASETTI, L.; VOLTERRA, E. Bioremediation of olive-mill wastewaters by composting. Waste Management and Research, v.13, p.509-518, 1995.

TRIPATHI, G.; BHARDWAJ, P. Comparative studies on biomass production, life cycles and composting efficiency of Eisenia fetida (Savigny) and Lampito mauritii (Kinberg). Bioresource Technology, v.92, p.275-283, 2004. 